
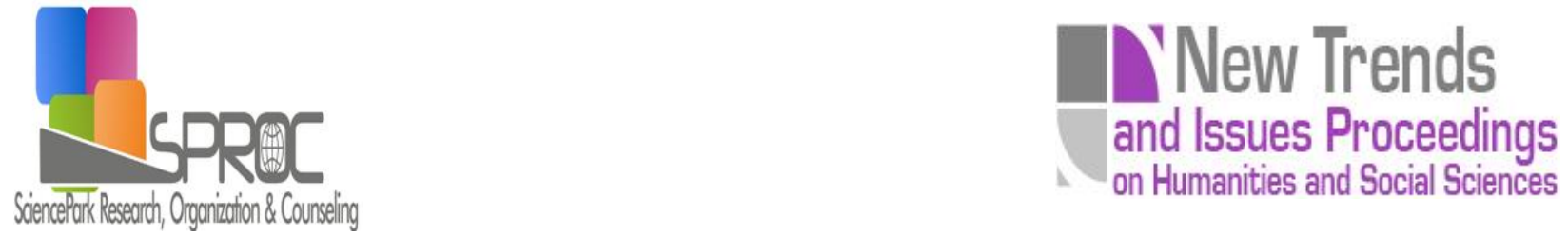

\title{
Regional differences in Italian students' performance: a simulation model
}

Francesca Costanza

Manuel Gentile *

Luciano Seta

Vito Pipitone

Erasmo Vassallo

Mario Allegra

Suggested Citation:

Abstract 
1. Introduction 
2. Brief introduction to system dynamics and applications to education

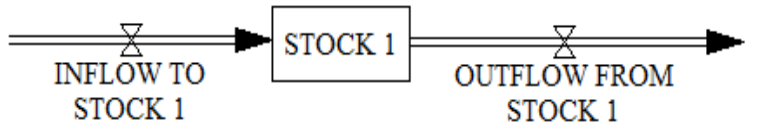

Fig. 1. Simplified Stock-and-Flow structure.

3. The model 


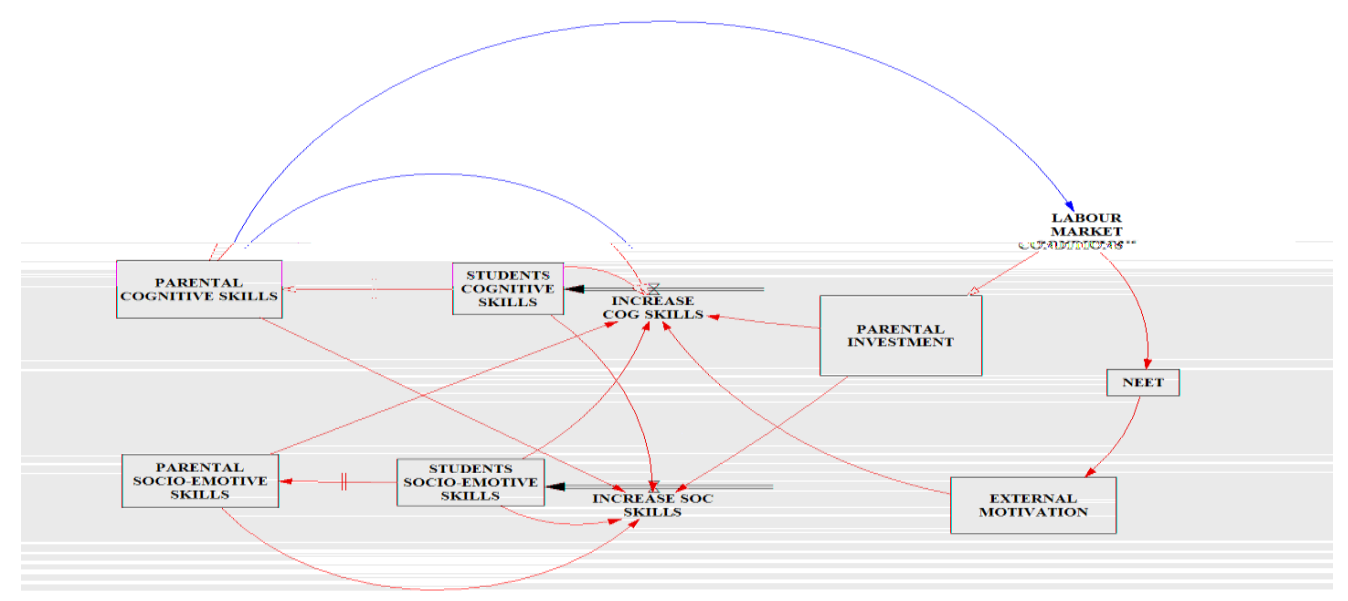

Fig. 2. Skill formation insight model 
4. Conclusions

References 


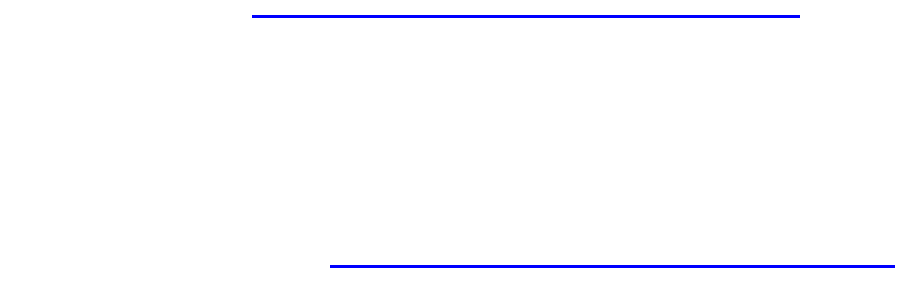

L'equite des systemes educatifs europeens. Un ensemble d'indicateurs. 

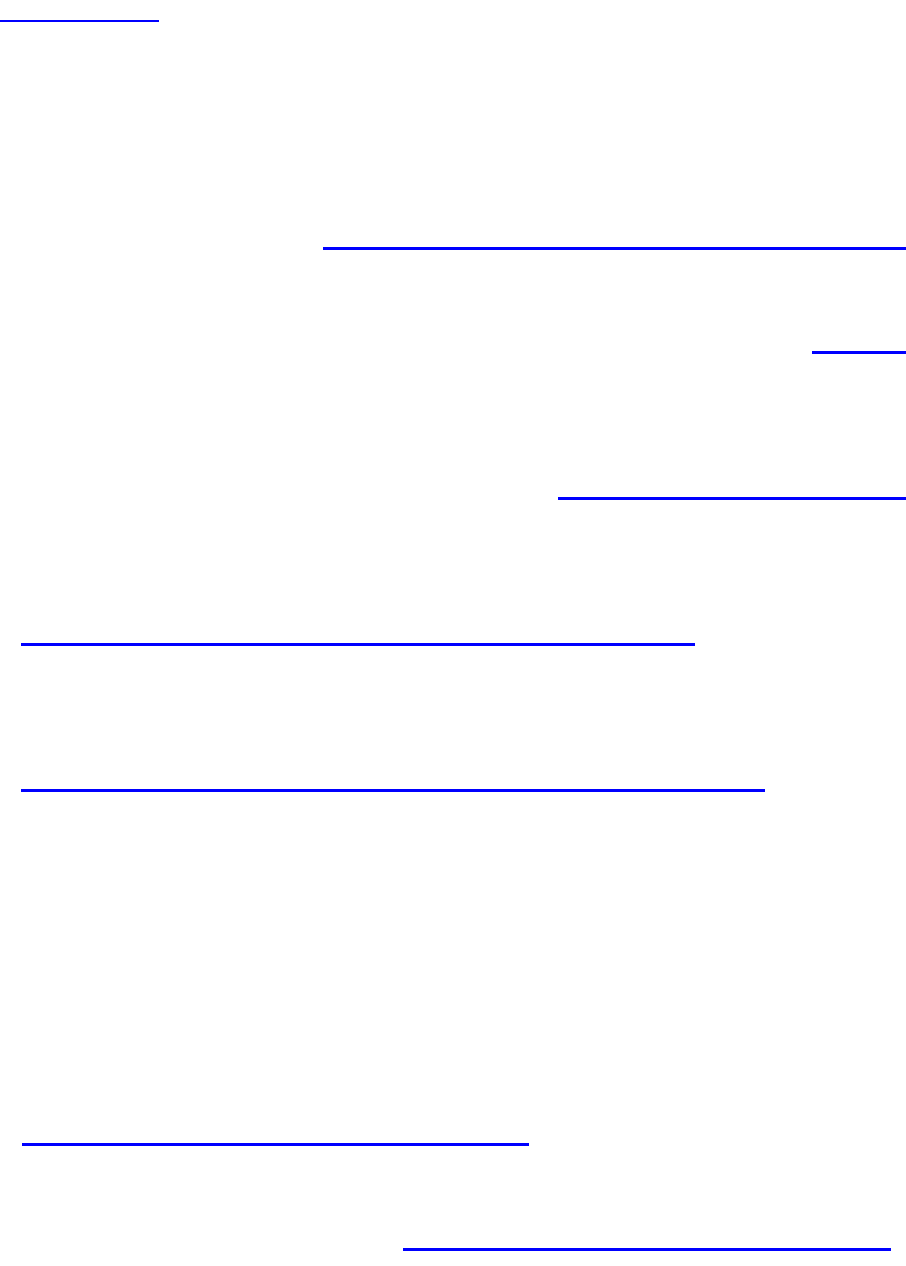